Original Article

\title{
The hotspots and trends of coronavirus disease 2019 (COVID-19) and physical therapy: a bibliometric and visual analysis
}

\author{
Conghui Li, MSc ${ }^{1)}$, Ziwei Li, BSc ${ }^{2)}$, Jiabao Guo, $\mathrm{PhD}^{3)}$, Yujie Yang, $\mathrm{PhD}^{4}$, \\ Chunyu LiU, Bsc ${ }^{2)}$, MengQi Wang, BSc ${ }^{2)}$, Yi Zhu, $\mathrm{PhD}^{2)^{*}}$ \\ 1) Academy of Medical Sciences, Zhengzhou University, China \\ 2) Department of Musculoskeletal Pain Rehabilitation, The Fifth Affiliated Hospital of Zhengzhou \\ University: 450000, China \\ 3) The Second School of Clinical Medicine, Xuzhou Medical University, China \\ 4) Department of Biomedical Sciences, City University of Hong Kong, China
}

\begin{abstract}
Purpose] With the COVID-19 pandemic, more and more articles have been published to explore the role of physical therapy on COVID-19. In order to analyze the research hotspots and the trends of physical therapy and COVID-19, we conducted bibliometric and visual analysis. [Methods] Data were collected from the Science Citation Index Expanded (SCI-EXPANDED) and Social Sciences Citation Index (SSCI) of the Web of Science Core Collect (WoSCC) from 2019 to 2021. CiteSpace and VOSviewer were used to perform the visual analysis of keywords and references to help quickly get key information. [Results] A total of 466 publications were retrieved. Exercise, sedentary behavior, and mental health were research hotspots. The relationship between exercise and immunity, as well as the management of COVID-19 patients after discharge were the research trends. [Conclusion] This study provided relevant information for future research. Findings suggested that physical therapy is beneficial for suspected or confirmed COVID-19 patients during isolation. It is hoped that academic exchanges can be quickly established in the face of infectious diseases. And in the future, we should focus on the rehabilitation of discharged patients.

Key words: Coronavirus disease 2019, Physical therapy, Bibliometrics
\end{abstract}

(This article was submitted Jul. 17, 2021, and was accepted Sep. 16, 2021)

\section{INTRODUCTION}

Coronavirus disease 2019 (COVID-19) is a global pandemic caused by severe acute respiratory syndrome coronavirus 2 (SARS-CoV-2). It often causes fever, cough, dyspnea, muscle pain, fatigue and other symptoms ${ }^{1}$. And it is highly contagious, which limits the movement of individuals and poses a huge challenge for governments to control the spread of the disease. According to published data, middle-aged and elderly people have a high infection rate, and patients with underlying diseases such as hypertension, diabetes, cancer and other diseases have a poor prognosis and a higher mortality rate ${ }^{1-3)}$. Such outbreaks of infectious diseases have attracted global attention and global research is carried out to treat the disease. Previous studies have shown that for lung diseases such as chronic obstructive pulmonary disease ${ }^{4)}$, pneumonia ${ }^{5)}$, and lung cancer $^{6}$, physical therapy has been shown to improve patients' physical function and health status. At the same time, exercise training is effective for most chronic diseases and microbiological infections, and it exerts preventive and therapeutic effects by affecting immune function, stimulating $N O$ synthesis, and regulating inflammatory response ${ }^{7)}$. Therefore, experts in the field of physical therapy have carried out relevant research and developed relevant guidelines to deal with this disease and

*Corresponding author. Yi Zhu (E-mail: zhuyi1010@163.com)

(C2021 The Society of Physical Therapy Science. Published by IPEC Inc.

(c) (i) $(-)$ This is an open-access article distributed under the terms of the Creative Commons Attribution Non-Commercial No Deriva-

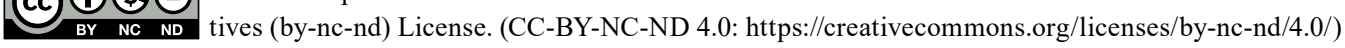


help alleviate the health problems of patients. COVID-19 is a public health issue of global concern. It is necessary to further increase interdisciplinary cooperation, strengthen international cooperation and exchange of experience, in order to reduce the impact of public health.

Bibliometric analysis is an effective method to count, analyze, and evaluate scientific publications and to quantitatively describe their impact on clinical practice over a period of time ${ }^{8,9)}$. At present, most bibliometrics are about the overview of COVID-19, and few bibliometric analyses have been conducted on physical therapy and COVID-19. In the face of a huge public health emergency such as COVID-19, it is particularly important to accurately grasp the research situation in the large number of studies that emerged in a short period of time. Therefore, this study aimed to summarize the research hotspots and the trends of physical therapy and COVID-19 through bibliometric analysis to provide a reference and more possibilities for future research and application.

\section{METHODS}

The data were from the Science Citation Index Expanded (SCI-EXPANDED) and Social Sciences Citation Index (SSCI) of the Web of Science Core Collect (WoSCC). Search words were created with reference to the MeSH Database in PubMed. The complete retrieval strategy is shown in Fig. 1a. The inclusion criteria were as follows: (1) documents were published between 2019 and 2021, (2) Document types only included articles and reviews, and (3) language was restricted to English. The data were collected on 10 May 2021.

CiteSpace $(5.7 . \mathrm{R} 5 \mathrm{~W})^{10,11)}$ and VOSviewer $(1.6 .16)^{12)}$, the bibliometric analysis tools, were applied to visualize knowledge networks and identity the hot topics in the field of research. CiteSpace has a powerful co-citation analysis function, and VOSviewer can show a smaller time span, so this paper used the two softwares together. In the network they generated, nodes represented keywords or cited references. The links between nodes represented co-occurrence or co-citation relationships. The label font and the node size indicated the frequency of node. And cold-hued nodes represented a relatively early time, while warm-hued nodes represented a relatively late time. In CiteSpace, and a node with a purple ring was considered a pivotal point that represented high centrality $(>0.1)$.

\section{RESULTS}

Obtaining relevant publications. The literature retrieval process is shown in Fig. 1a. A total of 824 publications were obtained. Through the screening strategy in Fig. 1b, our study eventually included 466 English publications from 12 May 2020 to 1 March 2021, including 390 articles and 76 reviews. It can be seen that in the face of the epidemic, researchers are very concerned about the COVID-19 and have conducted more studies.

Analysis of keywords. CiteSpace generated 86 keywords, and the top 10 keywords on the basis of frequency and centrality are shown in Table 1. And Fig. 2a shows the time of keywords through VOSviewer, which could represent the hotspots and trend of research in this field to some extent. Current research hotspots could be classified as dietary habits, social isolation, sedentary behavior, and mental health. Specially, COVID-19, physical activity, exercise, lockdown, pandemic, depression, and mortality were considered hot words.

Analysis of co-cited References. Table 2 presents co-cited references with co-citation counts more than 30 . These six publications were considered to be important. Through the clustering co-cited references, the top 4 clusters in the timeline map were shown in Fig. 2b, which were cluster No. 0 physical activity, cluster No. 1 gender, cluster No. 2 confinement, and cluster No. 3 exercise. These clusters were consistent with the current research hotspots.

a

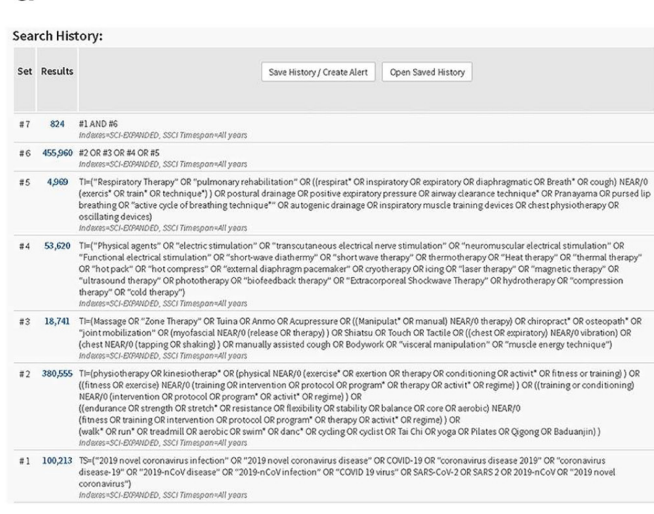

b

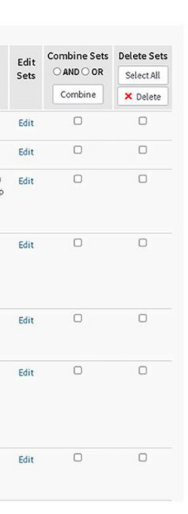

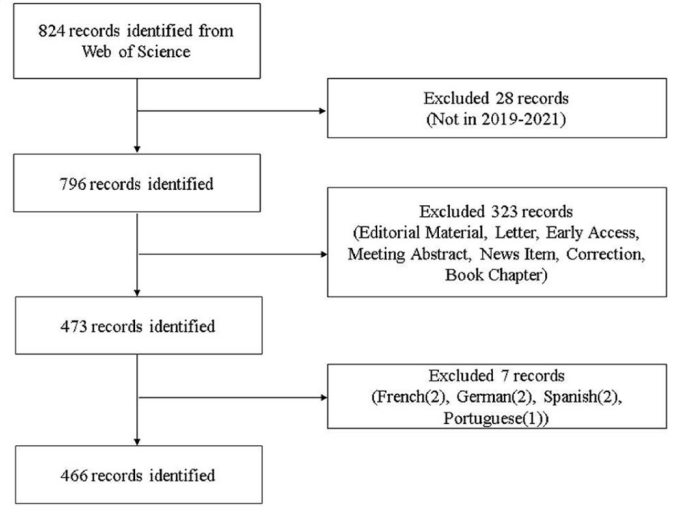

Fig. 1 a. The search strategy and results from WoSCC b. Flow chart of inclusion in this study. 


\section{DISCUSSION}

This study aimed to present a bibliometric analysis of studies on COVID-19 and physical therapy. Using CiteSpace and VOSviewer, we analyzed the important information presented by the scientific map to identify research hotspots and trends.

Despite the sudden outbreak of COVID-19, the researchers were quick to make clinical practice recommendations for

Table 1. The top 10 key words on COVID-19 and physical therapy

\begin{tabular}{clrlc}
\hline Rank & \multicolumn{1}{c}{ Key words $(*)$} & Count & \multicolumn{1}{c}{ Key words $(* *)$} & Centrality \\
\hline 1 & COVID-19 $(0.12)$ & 228 & Disease (18) & 0.24 \\
2 & Physical activity $(0.20)$ & 121 & Exercise (85) & 0.23 \\
3 & Exercise (0.23) & 85 & Physical activity (121) & 0.20 \\
4 & Coronavirus (0.05) & 56 & Mortality (18) & 0.15 \\
5 & Sars-cov-2 (0.04) & 43 & Stress (16) & 0.13 \\
6 & Pandemic (0.07) & 37 & COVID-19 (228) & 0.12 \\
7 & Lockdown (0.01) & 36 & Reliability (12) & 0.12 \\
8 & Health (0.02) & 33 & Public health (17) & 0.11 \\
9 & Depression (0.08) & 30 & Lockdown (36) & 0.10 \\
10 & Sedentary behavior (0.08) & 25 & Pandemics (8) & 0.09 \\
\hline
\end{tabular}

*: The numbers in brackets represented the centrality of the key words.

**: The numbers in brackets represented the count of the key words.

a

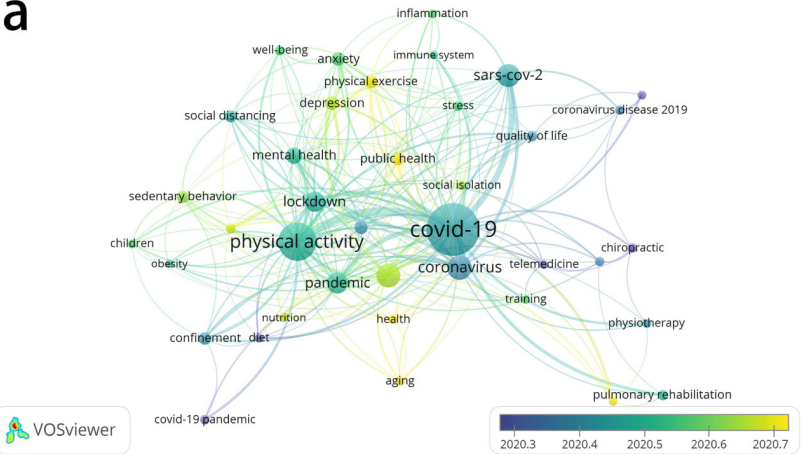

b

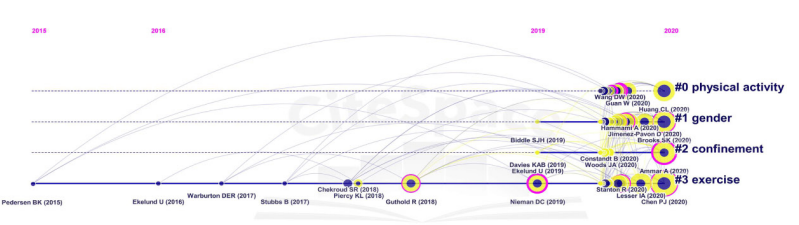

Fig. 2. Research trends of COVID-19 in the field of physical therapy (a. the time map of keywords b. the timeline map of co-cited references clusters).

Table 2. The top 6 co-cited references that related to COVID-19 in the field of physical therapy

\begin{tabular}{|c|c|c|c|c|}
\hline Rank & Co-cited reference & Count & First author & Journal \\
\hline 1 & $\begin{array}{l}\text { Coronavirus disease (COVID-19): the need to maintain } \\
\text { regular physical activity while taking precautions } \mathrm{s}^{13)}\end{array}$ & 57 & Peijie Chen & Journal of Sport and Health Science \\
\hline 2 & $\begin{array}{l}\text { The psychological impact of quarantine and how to reduce it: } \\
\text { rapid review of the evidence }{ }^{14)}\end{array}$ & 51 & $\begin{array}{l}\text { Samantha K. } \\
\text { Brooks }\end{array}$ & Lancet \\
\hline 3 & $\begin{array}{l}\text { Effects of COVID-19 home confinement on eating behaviour } \\
\text { and physical activity: results of the ECLB-COVID19 } \\
\text { International Online Survey }{ }^{15}\end{array}$ & 50 & Achraf Ammar & Nutrients \\
\hline 4 & $\begin{array}{l}\text { Clinical features of patients infected with } 2019 \text { novel } \\
\text { coronavirus in Wuhan, China }{ }^{1)}\end{array}$ & 46 & Chaolin Huang & Lancet \\
\hline 5 & $\begin{array}{l}\text { The impact of COVID-19 on physical activity behavior and } \\
\text { well-being of Canadians people }{ }^{16)}\end{array}$ & 38 & Iris A. Lesser & $\begin{array}{l}\text { International Journal of Environmental } \\
\text { Research and Public Health }\end{array}$ \\
\hline 6 & $\begin{array}{l}\text { Physical exercise as therapy to fight against the mental and } \\
\text { physical consequences of COVID-19 quarantine: special } \\
\text { focus in older people }{ }^{17)}\end{array}$ & 37 & $\begin{array}{l}\text { David } \\
\text { Jiménez-Pavón }\end{array}$ & Progress in Cardiovascular Diseases \\
\hline
\end{tabular}


physiotherapy management. Peter Thomas et al. suggested personnel planning and response measures, medical management strategies, and physical therapy management principles for physiotherapists when managing hospitalized patients who are confirmed or suspected to have COVID-19. These principles included respiratory interventions in the ICU, precautions for personal protective equipment, and exercise and rehabilitation programs ${ }^{18}$. The highly cited literature focused not only on rehabilitation management of COVID-19, but also on health-related impacts of measures taken by the government to reduce the spread of novel coronavirus. Although home confinement was a necessary measure, people's physical health, living habits, and mental health were affected to some extent ${ }^{19,20)}$. Researchers in various countries assessed the changes in physical activity, eating habits and mental health during confinement by means of online surveys, and they found the reduction in physical activity and changes in dietary habits associated with confinement had a negative impact on health ${ }^{15,16)}$. So the health problems associated with isolation should not be ignored. The government should inform the public of the significance of quarantine to avoid panic. And physical activity should be performed during home isolation to avoid other health risks ${ }^{21,22)}$.

Initially, the study went roughly from the COVID-19 pandemic to behavioral changes. In addition to the increasing symptoms of anxiety and depression, some studies showed that inactivity and prolonged sitting increased the risk of chronic diseases. Chronic diseases in turn increased the likelihood of hospitalization with COVID-19 infection ${ }^{23)}$. Moreover, exercise is associated with increased immune function. Moderate and high intensity exercise could increase the expression of natural killer cells, CD8+ T lymphocytes, and anti-inflammatory cytokines, which play an important role in the immune system ${ }^{24,25)}$. Data from related studies also suggested that a negative correlation exists between exercise and disease, and exercise could reduce mortality of respiratory diseases ${ }^{26,27)}$. Therefore, physical therapy interventions were recommended in the relevant guidelines for COVID-19. In addition to the exercise for patients with COVID-19 mentioned earlier, the guidelines also recommended some respiratory physical therapies. For different stages of disease, physiotherapists should take different physical therapy measures. Commonly used respiratory interventions include airway clearance technology, thoracic expansion, cough etiquette, prone positioning, positive expiratory pressure therapy, and mechanical ventilation. In addition, respiratory muscle training (including inspiratory and expiratory muscles) is recommended for patients on prolonged mechanical ventilation $^{18,28,29)}$. These interventions improve vital capacity, promote sputum discharge, and improve symptoms such as dyspnea. In practice, physiotherapists should reduce the risk of airborne transmission and take personal protective measures. For patients with COVID-19 in the acute phase, respiratory muscle training, pursed lips breathing, incentive spirometer, and bubble PEP are not recommended ${ }^{30}$. For patients with COVID-19, Rik Gosselink asked the following two questions ${ }^{31)}$ : How do we follow up with patients to identify their health status after COVID-19? What should be done for patients discharged from ICU? The findings of previous studies suggest that we should pay attention to the rehabilitation of COVID-19 patients after discharge. In addition, we also found that research for COVID-19 in the field of physical therapy has been published protocols for systematic review and meta-analysis ${ }^{32-34)}$. For patients with COVID-19, researchers have begun to conduct evidence-based studies for physical therapy. We believe that as prospective studies are published, more evidence will be provided.

This is the first bibliometric study of COVID-19 in the field of physical therapy. We summarized the current research hotspots and trends of COVID-19 and physical therapy to find possible ideas for future research and application. Some limitations were present that may lead to bias. First, because of the limitations of our own language, only English literature was included in the study. Second, this study only included articles and reviews. In the future, we should focus on the post-discharge rehabilitation of COVID-19 patients. Besides, we need to think about how to quickly build international cooperation and how to quickly intervene in physical therapy in the face of infectious diseases.

\section{Funding and Conflict of interest}

This study was supported by National Natural Science Foundation of China (grant 81860875). Conghui Li and Ziwei Li are the co-first authors. The authors have no conflicts of interest to declare.

\section{REFERENCES}

1) Huang C, Wang Y, Li X, et al.: Clinical features of patients infected with 2019 novel coronavirus in Wuhan, China. Lancet, 2020, 395: 497-506. [Medline] [CrossRef]

2) Chen N, Zhou M, Dong X, et al.: Epidemiological and clinical characteristics of 99 cases of 2019 novel coronavirus pneumonia in Wuhan, China: a descriptive study. Lancet, 2020, 395: 507-513. [Medline] [CrossRef]

3) Jin Y, Yang H, Ji W, et al.: Virology, epidemiology, pathogenesis, and control of COVID-19. Viruses, 2020, 12: 12. [Medline] [CrossRef]

4) Arbillaga-Etxarri A, Gimeno-Santos E, Barberan-Garcia A, et al.: Long-term efficacy and effectiveness of a behavioural and community-based exercise intervention (Urban Training) to increase physical activity in patients with COPD: a randomised controlled trial. Eur Respir J, 2018, 52: 52. [Medline] [CrossRef]

5) López-López L, Torres-Sánchez I, Rodríguez-Torres J, et al.: Does adding an integrated physical therapy and neuromuscular electrical stimulation therapy to standard rehabilitation improve functional outcome in elderly patients with pneumonia? A randomised controlled trial. Clin Rehabil, 2019 , 33: $1757-1766$. [Medline] [CrossRef]

6) Messaggi-Sartor M, Marco E, Martínez-Téllez E, et al.: Combined aerobic exercise and high-intensity respiratory muscle training in patients surgically treated for non-small cell lung cancer: a pilot randomized clinical trial. Eur J Phys Rehabil Med, 2019, 55: 113-122. [Medline] [CrossRef]

7) Green DJ, Maiorana A, O’Driscoll G, et al.: Effect of exercise training on endothelium-derived nitric oxide function in humans. J Physiol, 2004 , 561: 1-25. 
[Medline] [CrossRef]

8) Cooper ID: Bibliometrics basics. J Med Libr Assoc, 2015, 103: 217-218. [Medline] [CrossRef]

9) Thompson DF, Walker CK: A descriptive and historical review of bibliometrics with applications to medical sciences. Pharmacotherapy, 2015, 35: 551-559. [Medline] [CrossRef]

10) Chen C: CiteSpace II: Detecting and visualizing emerging trends and transient patterns in scientific literature. J Am Soc Inf Sci Technol, 2006, 57: 359-377. [CrossRef]

11) Synnestvedt MB, Chen C, Holmes JH: CiteSpace II: visualization and knowledge discovery in bibliographic databases. AMIA Annu Symp Proc, 2005, 724-728. [Medline]

12) van Eck NJ, Waltman L: Software survey: VOSviewer, a computer program for bibliometric mapping. Scientometrics, 2010, 84: 523-538. [Medline] [CrossRef]

13) Chen P, Mao L, Nassis GP, et al.: Coronavirus disease (COVID-19): the need to maintain regular physical activity while taking precautions. J Sport Health Sci, 2020, 9: 103-104. [Medline] [CrossRef]

14) Brooks SK, Webster RK, Smith LE, et al.: The psychological impact of quarantine and how to reduce it: rapid review of the evidence. Lancet, 2020, 395: 912-920. [Medline] [CrossRef]

15) Ammar A, Brach M, Trabelsi K, et al.: Effects of COVID-19 home confinement on eating behaviour and physical activity: results of the ECLB-COVID19 International Online Survey. Nutrients, 2020, 12: 12. [Medline] [CrossRef]

16) Lesser IA, Nienhuis CP: The impact of COVID-19 on physical activity behavior and well-being of Canadians. Int J Environ Res Public Health, 2020,17 : 17. [Medline] [CrossRef]

17) Jiménez-Pavón D, Carbonell-Baeza A, Lavie CJ: Physical exercise as therapy to fight against the mental and physical consequences of COVID-19 quarantine: special focus in older people. Prog Cardiovasc Dis, 2020, 63: 386-388. [Medline] [CrossRef]

18) Thomas P, Baldwin C, Bissett B, et al.: Physiotherapy management for COVID-19 in the acute hospital setting: clinical practice recommendations. J Physiother, 2020, 66: 73-82. [Medline] [CrossRef]

19) López-Bueno R, Calatayud J, Andersen LL, et al.: Immediate impact of the COVID-19 confinement on physical activity levels in Spanish adults. Sustainability, 2020, 12.

20) Romero-Blanco C, Rodríguez-Almagro J, Onieva-Zafra MD, et al.: Physical activity and sedentary lifestyle in university students: changes during confinement due to the COVID-19 pandemic. Int J Environ Res Public Health, 2020, 17: 17. [Medline] [CrossRef]

21) Chen P, Mao L, Nassis GP, et al.: Returning Chinese school-aged children and adolescents to physical activity in the wake of COVID-19: actions and precautions. J Sport Health Sci, 2020, 9: 322-324. [Medline] [CrossRef]

22) Martinez-Ferran M, de la Guía-Galipienso F, Sanchis-Gomar F, et al.: Metabolic impacts of confinement during the COVID-19 pandemic due to modified diet and physical activity habits. Nutrients, 2020, 12: 12. [Medline] [CrossRef]

23) CDC COVID-19 Response Team: Preliminary estimates of the prevalence of selected underlying health conditions among patients with coronavirus disease 2019-United States, February 12-March 28, 2020. MMWR Morb Mortal Wkly Rep, 2020, 69: 382-386. [Medline] [CrossRef]

24) Campbell JP, Riddell NE, Burns VE, et al.: Acute exercise mobilises CD8+ T lymphocytes exhibiting an effector-memory phenotype. Brain Behav Immun, 2009, 23: 767-775. [Medline] [CrossRef]

25) Bigley AB, Rezvani K, Chew C, et al.: Acute exercise preferentially redeploys NK-cells with a highly-differentiated phenotype and augments cytotoxicity against lymphoma and multiple myeloma target cells. Brain Behav Immun, 2014, 39: 160-171. [Medline] [CrossRef]

26) Williams PT: Dose-response relationship between exercise and respiratory disease mortality. Med Sci Sports Exerc, 2014, 46: 711-717. [Medline] [CrossRef]

27) Wu S, Ma C, Yang Z, et al.: Hygiene behaviors associated with influenza-like illness among adults in Beijing, China: a large, population-based survey. PLoS One, 2016, 11: e0148448. [Medline] [CrossRef]

28) Felten-Barentsz KM, van Oorsouw R, Klooster E, et al.: Recommendations for hospital-based physical therapists managing patients with COVID-19. Phys Ther, 2020, 100: 1444-1457. [Medline] [CrossRef]

29) Zhu Y, Wang Z, Zhou Y, et al.: Summary of respiratory rehabilitation and physical therapy guidelines for patients with COVID-19 based on recommendations of World Confederation for Physical Therapy and National Association of Physical Therapy. J Phys Ther Sci, 2020, 32: 545-549. [Medline] [CrossRef]

30) Lazzeri M, Lanza A, Bellini R, et al.: Respiratory physiotherapy in patients with COVID-19 infection in acute setting: a Position Paper of the Italian Association of Respiratory Physiotherapists (ARIR). Monaldi Arch Chest Dis, 2020, 90: 90. [Medline] [CrossRef]

31) Polastri M, Nava S, Clini E, et al.: COVID-19 and pulmonary rehabilitation: preparing for phase three. Eur Respir J, 2020, 55: 55. [Medline] [CrossRef]

32) Ding Y, Guo C, Yu S, et al.: The effect of dance-based mind-motor activities on the quality of life in the patients recovering from COVID-19: a protocol for systematic review and meta-analysis. Medicine (Baltimore), 2021, 100: e25102. [Medline] [CrossRef]

33) Luo Z, Chen Y, Wang L, et al.: The effect of Tai Chi on the quality of life in the elderly patients recovering from coronavirus disease 2019: a protocol for systematic review and meta-analysis. Medicine (Baltimore), 2020, 99: e23509. [Medline] [CrossRef]

34) Shi Y, Wen D, Wang H, et al.: Tai Chi for coronavirus disease 2019 in recovery period: a protocol for systematic review and meta analysis. Medicine (Baltimore), 2020, 99: e21459. [Medline] [CrossRef] 